\title{
Book Review: Online, Blended, and Distance Education: Building Successful Programs in Schools
}

\author{
Anne Roycroft, EdD \\ Fuel Education
}

Editors: Tom Clark and Michael Barbour. (2015). Online, Blended, and Distance Education: Building Successful Programs in Schools. Sterling, VA: Stylus Publishing. 239 pages. ISBN: 978-1-62036-163-4 (cloth)

Editors Tom Clark and Michael Barbour assemble an array of research and case studies from some of today's leading scholars in digital learning in this user-friendly compilation. With over 30 years of experience in online learning research between them, Clark and Barbour's wisdom is evident in their choices of contributors and themes. The book provides a greatly needed overview of research in online teaching and learning, which also shows that there is ample opportunity for investigation and innovation. Chapters on instructional design, technology infrastructure, and equitable access provide useful summaries for program planning, while the variety of case studies will no doubt trigger expanded investigation and future study.

Clark and Barbour anchor Part One of their book with an "Overview" chapter. This chapter is an essential historical chronology, going back to educational radio and other distance education programs in 1921. Their brief review reminds us just how far digital learning has come, and in a relatively short time.

Part Two, "Research and Practice," assembles six chapters on useful topics for practitioners and beginning researchers. The chapters establish common definitions, provide a historical and thematic review essential to our understanding of digital learning today, add evidence from a variety of implementations, and add a necessary global perspective to the book.

Chapter 2, written by Kathryn Kennedy and Leanna Archambault, explores quality online teaching. Central to their chapter is an overview of the research on online learning already available and information about the current standards for online teaching published by Southern Region Education Board (SREB) and the International Association for K-12 Online Learning (iNACOL). They also provide a brief look at the ways online teaching is supported through teacher education, preservice, and in-service programs, which they argue are critical next steps for quality online programming.

In Chapter 3, Christy Keeler focuses on instructional design and explores some of the ways online courses are developed as commercial products. While Keeler's general observations about the models of design 
may not hold true for all courses today, the chapter is an essential starting point for understanding online course development, student-teacher communication, instructional strategies, and assessment strategies. Keeler concludes, appropriately, with a reminder that new opportunities are quickly gathering steam, so important updates are warranted for this section.

As with Keeler's work, Chapter 4, authored by Rob Darrow, will need a continual update, as the world of online technology moves so quickly. Darrow focuses on the technology infrastructure necessary for online programs today and provides important decision-making tips for administrators and technology leaders. While Darrow references mobile technologies, Web 2.0 tools, social media, social constructivism, and OER, a summary of the avalanche of innovation that has since occurred in each of those areas would make valuable addendum.

In Chapter 5, Richard Ferdig, Cathy Cavanaugh, and Joe Friedhoff explore research in K-12 online and blended learning, while Chapter 6 is an exploration of cyber charter schools by Victoria Raish and Ali Carr-Chellman. Both chapters remind us about the frequently debated question, "Does online learning work?” and point out the quality disparity prevalent in online courses and programs.

Clark and Barbour conclude Part Two of their book with a must-read chapter on accessibility by Ray Rose, Alese Smith, Karen Johnson, and David Glick. The authors not only provide a helpful checklist in their appendix but also point out some of the common issues of access that must be addressed when planning new programs and updating existing ones. Whether through district firewalls or restrictive conditions for individual student access, such as pretests, programs often unknowingly limit equitable access to online resources. The reader will be surprised that the chapter is focused as much on implementation by teacher and school as it is on instructional design and web development.

The case studies that dominate Part Three of the book allow us to see the many ways online and blended learning have been used, evaluated, and modified in noteworthy programs around the world. Chapters 8 through 16 also provide examples for readers to follow, whether in research design or program innovation. Clark and Barbour provide us with a smorgasbord of short studies, from an impact study with the North Carolina Virtual Public School to a report on the implementation of a variety of blended charter schools across the United States, and from a case study on a public virtual high school in Clark County, Nevada, to a study of an online private school in Ontario, Canada. Other international studies from Nepal, Australia, the United Kingdom, and Korea provide an impressive variety of evidence of the global potential of digital learning. A nice addition to these studies is Chapter 9, the story of the development of the online teaching endorsement program at Boise State University, by Dazhi Yang and Kerry Rice. As Cathy Cavanaugh notes in her foreword, models such as those presented in this book help us learn from the successful experiences and innovations of trailblazers, as well as from their missteps.

Clark and Barbour conclude with Part Four, a summary not only of the book but also of the themes shared by its writers. They attempt to decipher the best practices and themes that will impact the future of digital learning and present their perception of eight key trends. They set the stage for the next edition as we watch for innovation to lead us to growth in personalized learning opportunities for students, among other exciting opportunities.

This book is a smart selection for administrators and technology coordinators, and a timely supplement for college-level courses in school improvement, online teaching and learning, policy, and leadership. Online teachers and leaders will find the book helpful in reflecting on the accomplishments of the blended and online learning movement but also a reminder of the potential that still remains. Graduate students will find the book a useful introduction to research, with an abundance of ideas for new projects. 